\title{
Time to get our four priorities right: An 8 year prospective investigation of 1326 player-seasons to identify the frequency, nature, and burden of time-loss injuries in elite Gaelic football
}

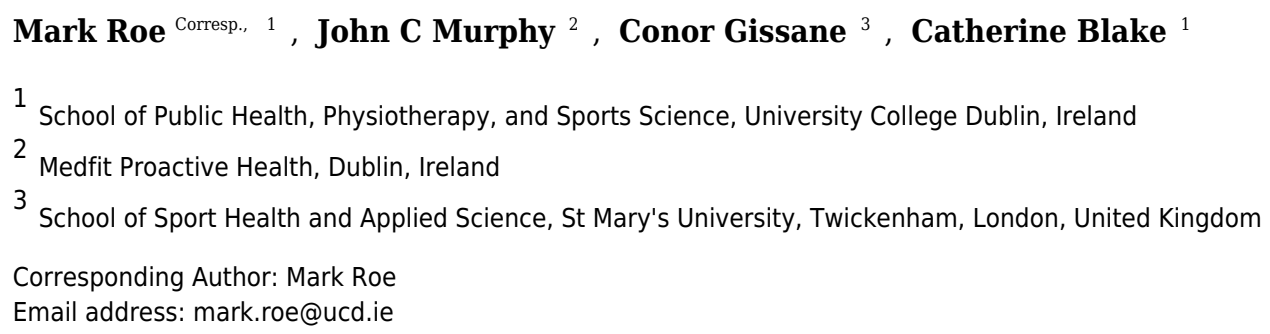

Managing injury risk requires an understanding of how and when athletes sustain certain injuries. Such information guides organisations in establishing evidence-based priorities and expectations for managing injury risk. In order to minimise the impact of sports injuries, attention should be directed towards injuries that occur frequently, induce substantial time-loss, and elevate future risk. Thus, the current study aimed to investigate the rate at which elite Gaelic football players sustain different time-loss injuries during match-play and training activities. Datasets $(n=38)$ from elite Gaelic football teams $(n=17)$ were received bythe National GAA Injury Surveillance Database from 2008 to 2016. A total of 1614 time-loss injuries were analysed. Each season teams sustained 24.0 (IQR 16.0 32.0) and 15.0 (IQR 10.0 - 19.0) match-play and training injuries, respectively. When exposure was standardised to 1000 hours, greater rates of injury $(12.9,95 \% \mathrm{Cl} 11.7$ $14.3)$ and time-loss days $(13.4,95 \% \mathrm{Cl} 12.3-14.9)$ were sustained in match-play than in training. Acute injury rates were 3.1-times $(95 \% \mathrm{Cl} 2.7-3.4)$ greater than chronic/overuse injuries. Similarly, non-contact injury rates were 2.8-times $(2.5-3.2)$ greater than contact injuries. A total of $71 \%$ of injuries in elite Gaelic football affected five lower limb sites. Four lower limb-related clinical entities accounted for $40 \%$ of all time-loss injuries (hamstring, 23\%; ankle sprain, 7\%; adductor-related, 6\%; quadriceps strain, 5\%). Thus, most risk management and rehabilitation strategies need to be centered around five lower limb sites - and just four clinical entities. Beyond these, it may be highly unlikely that reductions in injury susceptibility can be attributed to specific team interventions. Thus, compliance with national databases is necessary to monitor injury-related metrics and future endeavors to minimise injury risk. 
1 Time to get our four priorities right: An 8 year prospective investigation of 1326 player2 seasons to identify the frequency, nature, and burden of time-loss injuries in elite Gaelic 3 football

4

5 Mark Roe ${ }^{1}$, John C Murphy², Conor Gissane ${ }^{3}$, Catherine Blake ${ }^{1}$

7 1. School of Public Health, Physiotherapy and Sports Science, Health Sciences Centre, 8 University College Dublin, Belfield, Dublin 4

9 2. Medfit Proactive Healthcare, Blackrock, Ireland

10 3. School of Sport, Health and Applied Science, St Mary's University, Waldegrave Road, 11 Strawberry Hill, Twickenham, London TW1 4SX

13 Corresponding Author Contact Details:

14 Mark Roe, School of Public Health, Physiotherapy and Sports Science, Health Sciences Center, 15 University College Dublin, Dublin 4, Ireland.

16 mark.roe@ucd.ie 
18

19

20

21

22

23

24

25

26

27

28

29

30

31

32

33

34

35

36

37

38

39

\section{Abstract}

Managing injury risk requires an understanding of how, where, and when athletes sustain certain injuries. Such information guides organisations in establishing evidence-based priorities and expectations for managing injury risk. In order to minimise the impact of sports injuries, attention should be directed towards injuries that occur frequently, induce substantial time-loss, and elevate future risk. Thus, the current study aimed to investigate the rate at which elite Gaelic football players sustain different time-loss injuries during match-play and training activities. Datasets $(n=38)$ from elite Gaelic football teams $(n=17)$ were received by the National GAA Injury Surveillance Database from 2008 to 2016. A total of 1606 time-loss injuries were analysed. Each season teams sustained 24.0 (IQR 16.0 - 32.0) and 15.0 (IQR 10.0 - 19.0) match-play and training injuries, respectively. When exposure was standardised to 1000 hours, greater rates of injury $(12.9,95 \% \mathrm{Cl} 11.7-14.3)$ and time-loss days $(13.4,95 \% \mathrm{Cl} 12.3-14.9)$ were sustained in match-play than in training. Acute injury rates were 3.1 -times $(95 \% \mathrm{Cl} 2.7-$ 3.4) greater than chronic/overuse injuries. Similarly, non-contact injury rates were 2.8-times $(2.5$ -3.2) greater than contact injuries. A total of $71 \%$ of injuries in elite Gaelic football affected five lower limb sites. Four lower limb-related clinical entities accounted for $40 \%$ of all time-loss injuries (hamstring, 23\%; ankle sprain, $7 \%$; adductor-related, $6 \%$; quadriceps strain, $5 \%$ ). Thus, most risk management and rehabilitation strategies need to be centred around five lower limb sites - and just four clinical entities. Beyond these, it may be highly unlikely that reductions in injury susceptibility can be attributed to specific team interventions. Thus, compliance with national databases is necessary to monitor injury-related metrics and future endeavours to minimise injury risk. 


\section{INTRODUCTION}

42 Gaelic football is a national sport of Ireland and has been governed by the Gaelic Athletic 43 Association (GAA) since 1884. Match-play is characterised by intermittent bouts of 44 multidirectional running as elite players reportedly cover $9200 \mathrm{~m}$, with $18 \%$ at a high-speed pace $45\left(>17 \mathrm{~km} \cdot \mathrm{h}^{-1}\right)(11)$. This equates to a relative distance of $132 \mathrm{~m} \cdot \mathrm{min}^{-1}$, however during periods of 46 match-play workloads can range between 190 to $230 \mathrm{~m} \cdot \mathrm{min}^{-1}(12)$.

Managing injury risk is essential for maximising player availability and team performance (6). The initial stage of this process involves establishing an injury profile for the given sport whilst accounting for the dynamic interactions between players and the activities they undertake $(1,9)$.

50 Thus, managing injury risk requires an understanding of how (i.e. inciting mechanism) and when 51 (i.e. inciting activity) athletes sustain certain injuries (e.g. hamstring strain) (30). In order to 52 minimise the impact of injuries in sports, attention can then be directed towards injuries that 53 occur frequently, induce substantial time-loss, and elevate future risk. Such information guides 54 sports organisations in establishing evidence-based priorities by being awarenss of "what 55 problems need to be focused on" when creating future strategies (22).

56 For instance, a lot of research and media attention is devoted to anterior cruciate ligament 57 (ACL) injuries, partially due to risk of developing osteoarthritis early in life (24). However, ACL 58 injuries only account for $2 \%$ of all injuries in elite Gaelic football (26). Although these infrequent 59 injuries result in an average of 300 days from sport (26), 83\% of elite athletes return to 60 performance levels comparable to their uninjured peers (25). Considering that $98 \%$ of injuries 61 will not involve the ACL, teams may not experience an ACL injury for 2 seasons, making it 62 impossible to evaluate the efficacy of specific risk management strategies at a single-team level. 63 Therefore, a need exists for injury surveillance data to support evaluations of team programs via comparsions to epidemiological data on specific clinical entities. In this way, stakeholders may move closer to consensus on what is an acceptable level of risk given awareness of evidence that is relevant, valid and reliable (23).

Additionally, injury risk management can only be guided with detailed reporting on specific clinical entities. This approach has been eluded to in relation to groin pain in athletes, however, it has not yet been expanded to an injury surveillance dataset encompassing all musculoskeletal injuries (21). Furthermore, the injury profile of specific activities has yet to be compared in 
71 Gaelic football. Thus, the current study aims to establish the frequency, nature, and burden of

72 time-loss injuries sustained in elite male Gaelic football.

\section{METHODS}

74 Three fundamental variables in epidemiological investigations are the interactions between 75 person, place, and time (9). In a sporting context these can be adapted to provide an 76 understanding of how (e.g. mechanism) and when (e.g. training, match-play) athletes of a given 77 age sustain specific injuries (e.g. ankle sprain). In the current study we apply these criteria to 78 describe the pattern of injured body regions among elite Gaelic football players. Players are 79 stratified into one of four groups according to age (18-20 years, 21-24 years, 25-29 years, >30 80 years). The activity during which the injury was sustained (i.e. training or match-play) indicated 81 place. Timing of injury was classified as per seasonal cycle, that is, preseason (weeks 1-7), 82 competitive cycle one (i.e. National League) (weeks 8-16), mid-season (weeks 17-22), or 83 competitive cycle two (i.e. Provincial-National Championship) (weeks 23-34).

84 Between 2008 and 2016, thirty eight datasets were received from elite male Gaelic football 85 teams $(n=17)$ enrolled in the National GAA Injury Surveillance Database. This equates to 1326 86 player-seasons. The involvement of each team ranged from 1-7 seasons. Following consent, 87 player anonymity was maintained and data protection assured in accordance with ethical 88 approval received from the Human Subjects Research Ethics Committee (LS-E-11-91) at 89 University College Dublin. The team medical doctor or Chartered Physiotherapist was 90 responsible for injury diagnosis (figures 1 and 2). Team medical staff were asked to confirm 91 whether all injury and exposure data had been provided before reports were generated. Non92 compliant teams were then excluded from analysis.

\section{Definitions}

94 Data were categorised as previously described (13). Injury was defined as "any injury that 95 prevents a player from taking a full part in all training and match play activities typically planned 96 for that day, where the injury has been there for a period greater than 24 hours from midnight at the end of the day that the injury was sustained" (4). A clinical diagnosis was also selected from a list or entered in free text form and later recoded to defined clinical entities or 'other' if appropriate. Date of partial fitness was defined as "the date the player is able to participate in training, but is not available for match selection". Date of full fitness was defined as "when the player has been able to take a full part in training and is available for match selection". 


\section{Data Analysis}

103 Data were analysed as previously described (15) using a statistical analysis software (IBM 104 SPSS Statistics 24.0). Continuous variables are reported as mean with 95\% confidence 105 intervals $(95 \% \mathrm{CI})$. Team rates are reported as median with interquartile ranges (IQR). Injury 106 incidences are reported per 1000 exposure hours. Injury burden (i.e. time-loss days per 1000 107 exposure hours) was calculated by multiplying mean time-loss by the injury incidence. Incidence 108 rate ratios (IRR) were calculated to compare injury risk across age groupings, injury types, and 109 match-play and training activities. IRRs were calculated by dividing a specific incidence metric 110 to that representing the injuries in all other sub-groups.

\section{RESULTS}

112 A total of 177854 exposure hours (17988 match-play; 159866 training) were reported. Time-loss 113 injuries $(n=1606)$ were reported for match-play $(n=896)$ and training activities $(n=616)$. An 114 additional 94 time-loss injuries $(5.9 \%, 95 \% \mathrm{Cl} 4.7-7.1)$ were associated with an insidious onset 115 as opposed to a specific activity.

\section{Team Rates}

117 The median number of injuries sustained per team each season was 42.0 (IQR 31.0 - 53.0). 118 Each season teams sustained 24.0 (IQR 16.0 - 32.0) and 15.0 (IQR 10.0 - 19.0) match-play 119 and training injuries, respectively. In total, 33.0 (IQR $22.0-45.0$ ) injuries were sustained during 120 competitive cycles (Table 1).

\section{Injury Site}

122 Match-play was associated with the onset of $54.4 \%$ (95\% Cl $51.7-57.2)$ lower limb, $75.6 \%$ $123(95 \% \mathrm{Cl} 69.0$ - 82.1) upper limb, 41.9\% (95\% Cl $32.4-51.4)$ trunk, and $62.2 \%(95 \% \mathrm{Cl} 48.9-$ $12475.6)$ head/neck injuries, respectively. Training was associated with the onset of $40.3 \%(95 \% \mathrm{Cl}$ 12537.5 - 48.2) lower limb, 23.2\% (95\% Cl 16.7 - 29.8) upper limb, 43.8\% (95\% Cl 34.3 - 53.3) 126 trunk, and $33.3 \%(95 \% \mathrm{Cl} 20.0-48.9)$ head/neck injuries, respectively.

127 The five most common injuries were lower limb related and accounted for $70.9 \%(95 \% \mathrm{Cl} 62.4-$ 128 78.9) of all time-loss injuries. However, the frequency of these common injuries differed 129 between match-play and training (table 2). Analysis of clinical entities revealed that four specific 130 injuries accounted for $40.9 \%(95 \% \mathrm{Cl} 35.6-46.1)$ of all injuries. These related to hamstring 
131 strains (23.0\%), ankle sprains (6.8\%), adductor-related groin pain (5.9\%), and quadriceps

132 strains (5.2\%). Quartile ranges identified that aside from these four clinical entities, each season

133 more than one-in-four teams will not sustain injuries identified as being the most common (table

134 3). These four clinical entities also accounted for $38.9 \%(95 \% \mathrm{Cl} 29.3-52.7)$ of all player 135 unavailability (table 4).

\section{Match-Play Injuries}

137 Match-play injuries accounted for 55.8\% (53.5 - 58.2) of all time-loss injuries. The lower limb 138 region was the most common site of match-play injury $(77.8 \%, 95 \% \mathrm{Cl} 75.1-80.3)$ followed by 139 the upper $\operatorname{limb}(14.2 \%, 95 \% \mathrm{Cl} 12.1-16.5)$, trunk $(4.9 \%, 95 \% \mathrm{Cl} 3.5-6.3)$, and head/neck 140 regions $(3.1 \%, 95 \% \mathrm{Cl} 2.0-4.2)$.

141 Most match-play injuries were classified as new $(78.0 \%, 95 \% \mathrm{Cl} 73.3-82.7)$ as opposed to 142 recurrent $(22.0 \%, 95 \% \mathrm{Cl} 17.3-26.7)$, were associated with an acute onset $(81.7 \%, 95 \% \mathrm{Cl}$ 14379.2 - 84.2) rather than chronic or overuse $(18.3 \%, 95 \% \mathrm{Cl} 15.8-20.8)$, and were incited by 144 non-contact mechanisms $(73.2 \%, 59.8-65.3)$ as opposed to contact between players $(36.8 \%$, $14595 \% \mathrm{Cl} 33.7-40.2)$.

146 Match-play was associated with the onset of 55.8\% (95\% Cl $53.4-58.2)$ of all new injuries and $14759.3 \%(95 \% \mathrm{Cl} 50.4-67.4)$ of all recurrent injuries. Furthermore, the proportions of all early $(<8$ 148 weeks), late (2-12 months), and delayed (>12 months) recurrent injuries occurring in match-play 149 were $59.3 \%(95 \% \mathrm{Cl} 50.4-67.4)$, 44.6\% (95\% Cl $36.7-52.5)$, and $44.6 \%(95 \% \mathrm{Cl} 32.5-$ 150 55.4), respectively.

151 Analysis of time-loss data revealed that 25.1\% (95\% Cl 21.7 - 28.5), 51.1\% (95\% Cl $47.5-$ $15255.4)$, and $23.8 \%(95 \% \mathrm{Cl} 20.0-27.0)$ of match injuries resulted in mild, moderate, and severe 153 time-loss, respectively.

\section{Training Injuries}

155 Training injuries most commonly occurred in the lower limb region $(83.6 \%, 95 \% \mathrm{Cl} 80.5-86.5)$ 156 followed by the upper limb $(6.3 \%, 95 \% \mathrm{Cl} 4.2-8.1)$, trunk $(7.5 \%, 95 \% \mathrm{Cl} 5.4-9.4)$, and 157 head/neck regions $(2.4 \%, 95 \% \mathrm{Cl} 1.3-3.9)$.

158 Training was associated with the onset of $38.7 \%(36.3-41.2)$ of all new injuries and $35.6 \%$ $159(95 \% \mathrm{Cl} 28.1-43.7)$ of all recurrent injuries. Furthermore, the proportions of early (<8 weeks), 
160 late (2-12 months), and delayed (>12 months) recurrent injuries that occurred during training 161 were $35.6 \%(95 \% \mathrm{Cl} 28.1$ - 43.7), 46.8\% (95\% Cl $38.1-54.7)$, and $47.0 \%(95 \% \mathrm{Cl} 36.1-$ 162 59.0), respectively.

163 Time-loss data revealed that $30.2 \%(95 \% \mathrm{Cl} 25.8-34.9), 50.4 \%(95 \% \mathrm{Cl} 45.7-55.8)$, and $16419.4 \%(95 \% \mathrm{Cl} 15.5-23.3)$ of training injuries resulted in mild, moderate, and severe time-loss, 165 respectively.

\section{Injury Incidence Across Age-Groups}

167 Overall injury incidence was $9.2(95 \% \mathrm{Cl} 8.8$ - 9.6) per 1000 exposure hours. The incidence of 168 acute injuries was 3.1-times $(95 \% \mathrm{Cl} 2.7$ - 3.4) greater than chronic/overuse injuries. Similarly, 169 non-contact injuries occurred 2.8-times (95\% Cl $2.5-3.2)$ more frequently than injuries incited 170 via contact between players. Injury incidence increased across age-groups with IRR greatest for 171 players aged $30+$ years $(1.51,95 \% \mathrm{Cl} 1.32-1.74)$ when compared to all other players 172 (supplementary table 1).

\section{Injury Incidence Between Match-Play and Training}

174 Match-play incidence $(49.8,95 \% \mathrm{Cl} 46.5$ - 53.0) was 12.9-times (95\% Cl 11.7 - 14.3) higher 175 than training incidence $(3.9,95 \% \mathrm{Cl} 3.6-4.3)$. The incidence and IRR of non-contact, contact, 176 acute, and chronic/overuse injuries between match-play and training are outlined in table 5 and 177 table 6.

178 The incidence of mild, moderate, and severe injuries was also compared between match-play 179 and training (table 7) whilst accounting for injury region. The IRR between match-play and 180 training injuries grew as the classification of severity increased (table 6).

\section{Time-Loss and Player Unavailability}

182 Match-play injuries accounted for a greater proportion of all time-loss $(51.8 \%, 95 \% \mathrm{Cl} 51.2-$ $18352.1)$ than training injuries $(33.8 \%, 95 \% \mathrm{Cl} 3.4-36.6)$. Match-play and training injuries resulted 184 in a total of $576(95 \%$ Cl 345.6 - 851.2) and $342(95 \%$ Cl 193.0 - 516.8) time-loss days per 185 team each season, respectively. The mean time-loss for match-play and training injuries was $18624.0(95 \%$ Cl 21.6 - 26.6) and 22.8 (95\% Cl 19.3 - 27.2) days, respectively. Although mean 187 time-loss overlaps considerably between these activities, injury burden (days lost per 1000 188 hours of exposure) was 13.4-times (95\% Cl $12.3-14.9)$ higher in match-play than in training 
189 (table 8). Lower limb injuries accounted for the majority $(79.3 \%, 95 \% \mathrm{Cl} 77.1-80.8)$ of player

190 unavailability. This trend was observed across all age-groups (supplementary Table 2).

\section{DISCUSSION}

192 The aim of the current study was to establish the rate at which elite Gaelic football players 193 sustain different time-loss injuries during match-play and training activities. Measures of central 194 tendency reveal that teams sustain 24 match-play and 15 training injuries per season. Injury 195 incidence per 1000 exposure hours is 12.9-times greater in match-play (49.8/1000 hours) than 196 in training (3.9/1000 hours). Essentially, teams are sustaining the vast majority of their injuries 197 during match-play despite only periodically playing competitive matches. The magnitude of 198 inequity between activity injury rates means that identification of factors influencing the onset of 199 match-play injuries should be prioritisied given their greater rate of occurrence.

\section{Emergence Of Match-Play Injury Patterns}

201 Despite contact injuries being 18.0-times more frequent in match-play than in training, 73\% of 202 match-play injuries were classified as non-contact. Furthermore, most match-play injuries were 203 classifed as new (78\%) and acute (82\%) suggesting an adverse relationship between player's 204 capacities and imposed match-play demands. Thus, factors such as contact between players 205 and deficits from previous or ongoing conditions are not associated with the onset of most 206 match-play injuries. This prompts the question: why do acute, non-contact injuries occur more 207 frequently in match-play than in training? Although random events impact injury susceptibility, it 208 is unlikely that elite players become 13-times unluckier when playing match-play than playing 209 training.

210 A greater proportion of recurrent injuries (59\%) occurred in match-play than in training (36\%), 211 particularly during the immediate 8 weeks following return to sport (59\% v 30\%). Studies in elite 212 soccer players have observed decrements in lower limb strength following exposure to match213 play, particularly among previously injured players (18, 20). Although, elite Gaelic footballers 214 with previous hamstring injuries may have greater eccentric knee flexor strength on average 215 when compared to their uninjured peers, the likelihood of decrements following return to sport 216 was $51 \%$ with a $25 \%$ chance of between limb asymmetries exceeding $15 \%$ (29). The odds of 217 sustaining injury are also known to be greater among elite Gaelic football players with previous 218 injuries in comparison to their uninjured peers (15). Such findings may guide return to sport 
219 protocols and tailoring of risk management strategies among players with recent previous

220 injuries as unique management strategies may be required for this sub-cohort.

\section{Paradox of Performance-Focused Teams Sustaining Frequent Match-Play Injuries}

222 Considering that training aims to maximise the chances of the team succeeding in match-play, a

223 high match-play injury rate, largely constituted by non-contact and acute injuries, cannot coexist

224 with interventions to maximise player availability. The high rate of injuries (20, IQR $14.0-29.0)$

225 during the initial competitive cycle of the season suggests components of preseason

226 interventions offer little protection against early inseason exposures to injurious match-play

227 demands. Unavailabilty may impair the transition of early career players to senior squads by

228 reducing exposures to interventions to develop desired sport specific skills while promote

229 detraining during rehabilitation periods $(7,8,17)$.

230 The rate of injuries not associated with contact or chronic/overuse injuries in match-play 231 suggests emergence of an injury pattern distinct to training. This suggests scope for screening 232 studies to detect players especially vulnerable to match-play demands as it is questionable that 233 a truly random series of factors are driving this increased rate. However, difficulties in identifying 234 athletes are at greater risk of sustaining injury, due to modifiable factors, has been challenging 235 to date (2). While it is clear that most injuries in elite Gaelic football are sustained during match236 play, investigations of injury risk factors typically occur in preseason and thus, not periods 237 associated with frequent match-play exposures. This leads to a reliance on surrograte and 238 cross-sectional measures of injury risk to assess capacity to tolerate match-play demands for a 239 prolonged period of time. These findings suggest complex dynamics between an athlete's work 240 capacity, tolerance of sport specific stress, and injury.

241 The workloads imposed on athletes in match-play and training have yet to be compared in elite 242 Gaelic football. However, during training camp sessions players have reportedly covered $5417 \pm$ $243425 \mathrm{~m}$, of which $924.4 \pm 225 \mathrm{~m}$ was at $\geq 17 \mathrm{~km} . \mathrm{hr}$ or high-speed distance (10). This is $42 \%$ less 244 than the $9222 \pm 1588 \mathrm{~m}$ and $1596 \pm 594 \mathrm{~m}$ at $\geq 17 \mathrm{~km} . \mathrm{hr}$, reportedly covered in match-play (11). 245 Contextual factors such as seasonal cycle, opposition standard, tactical strategies, and match 246 outcome also impact these workloads (16). Despite being central to the activity during which 247 most injuries are sustained (i.e. match-play) these factors have yet to be considered by 248 screening tools.

249 Interpretating Epidemiological Data to Guide Selection of Screening Tools 
250 Understanding the extent of the injury problem is the first stge of reducing injury risk (19). This is

251 the key to designing risk management strategies as it guides researchers and practitioners with

252 an understanding of how, when, and where certain athletes sustain certain injuries (30). Results

253 of the current study show that training and match-play have different injury profiles as marked

254 by their distinct common injury sites, inciting mechanisms, types, and severity patterns. Thus,

255 the first stage in designing screening protocols for common injuries needs to consider the exact 256 injury of focus, during which activity and mechanism it mostly occurs, as well as the seasonal 257 cycle in which this screening protocol will be of some, and potentially, no utility.

258 Identifying what proportion of the problem would likely be solved by targeting certain injuries 259 needs to be considered. Considering how scarse training injuries occur, relative to the amount 260 of time to accumulate 1000 hours, addressing common match-play injuries may be a more 261 efficient endeavor for managing injury risk. Similarly, the sensitivity and specificity of screening 262 tools may vary across the season given the nature of activities associated with specific cycles 263 (3). For instance, there is scope to reduce time-loss if lower limb (79\%) or match-play (52\%) 264 injuries were addressed. Consensus on the management of common injuries is needed, even 265 moreso if the approach of frequent targeted screening during periods associated with the onset 266 of common injuries fails. Furthermore, considering the scarcity at which some injuries occur 267 each season, clinicians will be unlikely to statistically attribute changes in susceptibility to rates 268 of specific clinical entities to team interventions. The case load of a clinician across multiple 269 seasons will not facilitate the exploration of efficace interventions for reducing and rehabilitating 270 even the most common injuries on an elite Gaelic football team. Thus, participation in large271 scale injury surveillance databases is necessary to pool sufficient quantities of quality data to 272 monitor injury trends $(27,28)$.

\section{Time for Minimum Standards for Managing Common Injuries}

274 Hamstring, knee, ankle, groin, and quadricep injuries were the most common injuries in both 275 activities. These results mean that 3 out of 4 injuries in Gaelic football will affect one of five 276 lower limb sites. One in ten match-play injuries also affected the shoulder. Thus, it is important 277 that practitioners have a comprehensive understanding of methods to manage the assessment, 278 diagnosis, rehabilitation, and risk management of these specific injuries. Establishing minimum 279 reporting standards for these common injuries would reduce potential difficulties in these 280 procresses (5). These actions likely have implications for human resources operations 281 surrounding the recruitment and development of medical and coaching staff to deliver 
282 interventions specific to the sport. Epidemiological information as presented here can also guide

283 governing bodies in supporting medical resources at specific stages of the season associated

284 with a greater injury rate (e.g. competitive cycles) and higher treatment costs (14).

\section{Limitations}

286 A major limitation of the current study is the reliance on elite teams to voluntarily participate in 287 this injury surveillance project as it is not compulsory for teams to collect and share these data 288 with the governing body. Thus, it is currently impossible to establish longitudinal trends in the 289 rates of common injuries during match-play and training. The current study was also unable to 290 investigate the relationship between player characteristics, activity workloads, and risk of 291 sustaining a time-loss injury. This should be a priority for future research as completing 292 screening targeted at specific injuries more frequently may address limitations in traditional 293 approaches to injury screening while assisting in monitoring desired training responses.

\section{CONCLUSION AND METHODOLOGICAL CONSIDERATIONS}

295 Each season elite Gaelic football teams will sustain 24 match-play and 15 training time-loss 296 injuries. Regardless of activities, most injuries affect the lower limbs, are incited by non-contact 297 injury mechanisms, are associated with an acute onset, and result in 8-28 days absence from 298 sport. When time spent in activities is standardised to 1000 exposure hours, injuries occur 12.9299 time more frequently in match-play than in training. Similarly, time-loss days per 1000 hours are 300 13.4-times greater in match-play than in training. The utilisation of screening tools in future 301 studies should be targeted at seasonal cycles associated with the greatest injury risk to 302 maximise the potential to identify high risk players. 


\section{REFERENCES}

305 1. Auchincloss A, Diez Roux A. A New Tool for Epidemiology: The Usefulness of Dynamic306 Agent Models in Understanding Place Effects on Health. Am J Epidemiol 2008;1:1-8.

307 2. Bahr R. Why screening tests to predict injury do not work-and probably never will...: a $308 \quad$ critical review. Br J Sports Med 2016;50:776-80.

3. Bollars P, Claes S, Vanlommel L, Van Crombrugge K, Corten K, Bellemans J. The effectiveness of preventive programs in decreasing the risk of soccer injuries in Belgium: national trends over a decade. Am J Sports Med 2014;42:577-82.

4. Brooks J, Fuller CW, Kemp SP, Reddin D. Epidemiology of injuries in English professional rugby union: part 1 match injuries. Br J Sports Med 2005;39:757-66.

5. Delahunt E, Thorborg K, Khan K, Robinson P, Hölmich P, Weir A. Minimum reporting standards for clinical research on groin pain in athletes. Br J Sports Med. 2015;49:775-

6. Hägglund M, Waldén M, Magnusson $H$, Kristenson K, Bengtsson $H$, Ekstrand J. Injuries affect team performance negatively in professional football: an 11-year follow-up of the UEFA Champions League injury study. Br J Sports Med 2013;47:738-42.

7. Joo $\mathrm{CH}$. The effects of short-term detraining on exercise performance in soccer players. J Exerc Rehabil. 2016;12:54-9.

8. Koundourakis NE, Androulakis NE, Malliaraki N, Tsatsanis C, Venihaki M, Margioris AN. Discrepancy between exercise performance, body composition, and sex steroid response after a six-week detraining period in professional soccer players. PLoS One. 2014 19;9:e87803. 
326 9. Krieger N. Place, Space, and Health: GIS and Epidemiology. Epidemiol 2003;4:384-5.

327 10. Malone S, Hughes B, Roe M, Collins K, Buchheit M. Monitoring player fitness, fatigue status and running performance during an in-season training camp in elite Gaelic football. Sci Med Football, 16 Aug 2017. DOI: 10.1080/24733938.2017.1361040

11. Malone S, Solan B, Collins K, Doran D. The Positional Match Running Performance of

Elite Gaelic Football. J Strength Cond Res. 18 December 2015 doi: 10.1519/JSC.0000000000001309

12. Malone S, Solan B, Hughes B, Collins K. Duration specific Running performance in Elite

Gaelic Football. J Strength Cond Res. 2017 Apr 25. doi: 10.1519/JSC.0000000000001972.

13. Murphy JC, O’Malley E, Gissane G, Blake C. Incidence of injury in Gaelic football. A 4 year prospective study. Am J Sports Med 2012;40:2113-20.

14. Roe M, Blake C, Gissane C, Collins K. Injury Scheme Claims in Gaelic Games: A Review of 2007-2014. J Athl Train. 2016;51:303-8.

15. Roe M, Murphy JC, Gissane C, Blake C. Hamstring injuries in elite Gaelic football: an 8year investigation to identify injury rates, time-loss patterns and players at increased risk. Br J Sports Med 2016; 10 Nov 2016 doi:10.1136/bjsports- 2016-096401

16. Ryan S, Coutts AJ, Hocking J, Kempton T. Factors Affecting Match Running Performance in Professional Australian Football. Int J Sports Physiol Perform. 2017;9:119. Opportunity. Sports Med. 2016;46:305-13. 
348 18. Small K, Greig M, Lovell R. The effects of multidirectional soccer-specific fatigue on markers of hamstring injury risk. J Sci Med Sport 2010;13:120-5.

19. van Mechelen W, Hlobil H, Kemper HC. Incidence, severity, aetiology and prevention of sports injuries. A review of concepts. Sports Med 1992;14:82-9.

20. Wollin M, Thorborg K, Pizzari T. The acute effect of match play on hamstring strength and lower limb flexibility in elite youth football players. Scand J Med Sci Sports. $2017 ; 27: 282-8$

21. Weir A, Brukner P, Delahunt E, Ekstrand J, Griffin D, Khan KM, Lovell G, Meyers WC, Muschaweck U, Orchard J, Paajanen H, Philippon M, Reboul G, Robinson P, Schache AG, Schilders E, Serner A, Silvers H, Thorborg K, Tyler T, Verrall G, de Vos R, Vuckovic Z, Hölmich P. Doha agreement meeting on terminology and definitions in groin pain in athletes . Br J Sports Med. 2015;49:768-74.

22. Bahr R, Clarsen B, Ekstrand J. Why we should focus on the burden of injuries and illnesses, not just their incidence. Br J Sports Med. 2017 Oct 11. pii: bjsports-2017098160. doi: 10.1136/bjsports-2017-098160. [Epub ahead of print]

23. Quarrie KL, Brooks JHM, Burger N, Hume PA, Jackson S. Facts and values: on the acceptability of risks in children's sport using the example of rugby - a narrative review. Br J Sports Med. 2017;51:1134-1139.

24. Khan T, Alvand A, Prieto-Alhambra D, Culliford DJ, Judge A, Jackson WF, Scammell BE, Arden NK, Price AJ. ACL and meniscal injuries increase the risk of primary total knee replacement for osteoarthritis: a matched case-control study using the Clinical Practice Research Datalink (CPRD). Br J Sports Med. 2018 Jan 13. pii: bjsports-2017- 
371 25. Lai C, Ardern C, Feller J, Webster. Eighty-three per cent of elite athletes return to 372 preinjury sport after anterior cruciate ligament reconstruction: a systematic review with meta- analysis of return to sport rates, graft rupture rates and performance outcomes. $\mathrm{Br}$ J Sports Med 2018;52:128-138.

26. Roe M, Murphy J, Gissane C, Blake C. Anterior cruciate ligament injuries in elite Gaelic games. Physical Therapy in Sport 2017; 28:e10.

27. van Dyk N, van der Made AD, Timmins RG, Opar DA, Tol JL. There is strength in numbers for muscle injuries: it is time to establish an international collaborative registry. Br J Sports Med 2017. doi: 10.1136/bjsports-2016-097318 [Epub ahead of print].

28. Büttner FC, Delahunt E, Roe M. The Big Five: consensus considerations before a muscle injury registry revolution - stating the (not so) obvious. $\mathrm{Br} J$ Sports Med 2018. doi:10.1136/bjsports-2017-098643

29. Roe M, Malone S, Delahunt E, Collins K, Gissane C, Persson UM, Murphy JC, Blake C. Eccentric knee flexor strength profiles of 341 elite male academy and senior Gaelic football players: Do body mass and previous hamstring injury impact performance? Phys Ther Sport. 2018 Mar 1. pii: S1466-853X(17)30227-4. doi: 10.1016/j.ptsp.2018.01.006.

30. Roe M, Malone S, Blake C, Collins K, Gissane C, Büttner F, Murphy JC, Delahunt E. A six stage operational framework for individualising injury risk management in sport. Inj Epidemiol. 2017;4(1):26. 


\section{Figure 1}

Injury surveillance protocol

Outline of stages involved to recruit and obtain injury-related data from team

physiotherapists and medical doctors for the GAA National Injury Surveillance Database in 2008 to 2016. 
1. Training Exposure Hours

2. Number of Training Sessions

3. Match-Play Exposure Hours

4. Number of Matches
1. Date of Injury

2. Playing Position at Time of Injury

3. Body Region of Injury

4. Inciting Activity

5. Inciting Mechanism

6. Timing

7. Site of Injury

8. Side of Body

9. Main Tissue Injured

10. Injury Type

11. Injury Severity (Prognosis)

12. New or Recurrent

13. Injury Grade

14. Clinical Diagnosis

15. Other Ongoing Injuries

16. Date of Partial Fitness

17. Date of Full Fitness 
Figure 2

Data entry pathway for registering a time-loss injury

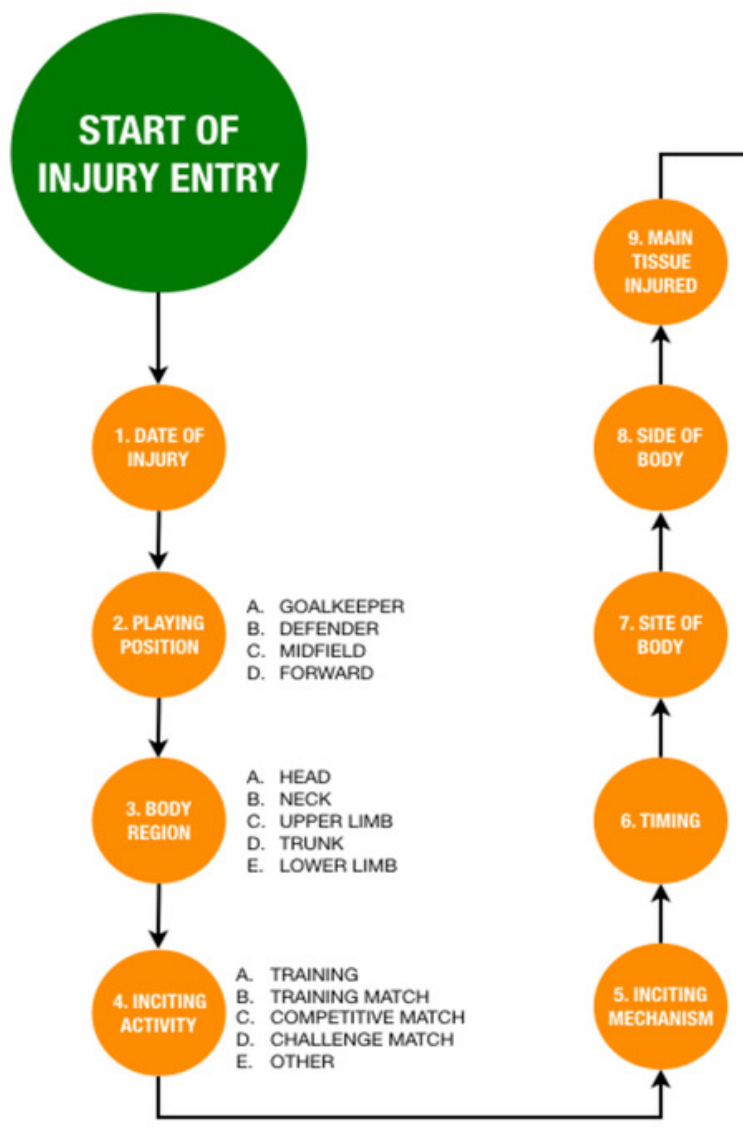

A. MUSCLE

B. TENDON

C. LIGAMENT

D. HAEMATOMA

E. FRACTIRE

F. JOINT

A. LEFT

B. RIGHT

C. BILATERAL

B. QUARTER 2

C. QUARTER 3

D. QUARTER 4

A. SPRINTING

B. TURNING

C. LANDING

D. KICKING

E. OTHER

F. GRADUAL ONSET

G. CONTACT (ANOTHER PLAYER)

G. NON-CONTACT
INJURY ENTRY

IS COMPLETE

A. ACUTE

B. CHRONIC

10. TYPE

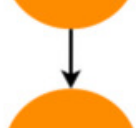

A. MILD
B. MODERATE

C. SEVERE

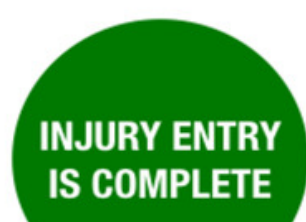

11. SEVERITY

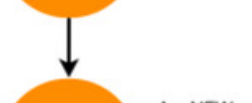

A. NEW
B. EARLY RECURRENT

B. EARLY RECURRENT

C. LATE RECURRENT
D. DELAYED RECURRENT
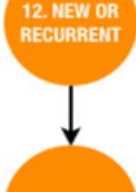

13. GRADE

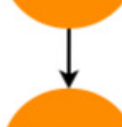

14. CLINICAL

DIAGNOSIS

(

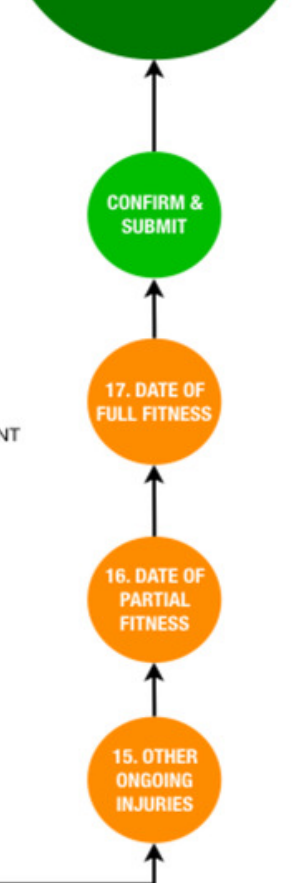




\section{Table $\mathbf{1}$ (on next page)}

Injury rates per team

Presented as median (interquartile range) per season. 


\section{Table 1 - Median (IQR) Team Injury Rates Per Season}

2

\begin{tabular}{|c|c|c|}
\hline & Median & Interquartile Range \\
\hline \multicolumn{3}{|l|}{ Team Rates } \\
\hline Total Injuries & 42.0 & $31.0-53.0$ \\
\hline Match-Play Injuries & 24.0 & $16.0-32.0$ \\
\hline Training Injuries & 15.0 & $10.0-19.0$ \\
\hline \multicolumn{3}{|l|}{ Region } \\
\hline Lower Limb & 33.0 & $24.0-45.0$ \\
\hline Upper Limb & 4.0 & $3.0-7.0$ \\
\hline Trunk & 2.0 & $1.0-5.0$ \\
\hline Head/Neck & 1.0 & $1.0-2.0$ \\
\hline \multicolumn{3}{|l|}{ Injury Type } \\
\hline Contact & 11.0 & $7.0-16.0$ \\
\hline Non-Contact & 30.0 & $21.0-39.0$ \\
\hline Acute & 32.0 & $26.0-36.0$ \\
\hline Chronic/Overuse & 9.0 & $5.0-13.0$ \\
\hline New & 31.0 & $23.0-43.0$ \\
\hline Recurrent & 9.0 & $7.0-11.0$ \\
\hline \multicolumn{3}{|l|}{ Severity } \\
\hline Mild & 11.0 & $6.0-17.0$ \\
\hline Moderate & 19.0 & $11.0-26.0$ \\
\hline Severe & 10.0 & $6.0-12.0$ \\
\hline \multicolumn{3}{|l|}{ Seasonal Cycle } \\
\hline Preseason & 4.0 & $2.0-7.0$ \\
\hline Competitive Cycle 1 & 20.0 & $14.0-29.0$ \\
\hline Midseason & 7.0 & $4.0-9.0$ \\
\hline Competitive Cycle 2 & 13.0 & $8.0-16.0$ \\
\hline
\end{tabular}


Table 2 (on next page)

Five most commonly injured sites

Presented with corresponding 95\% confidence intervals. 
1 Table 2 - Five Most Common Injured Sites

2

\begin{tabular}{|c|c|c|c|}
\hline & All injuries & Match-Play & Training \\
\hline 1 & Hamstring, $23.9 \%(21.9-26.0)$ & Hamstring, $23.1 \%(20.2-26.0)$ & Hamstring , $27.6 \%(24.2-31.2)$ \\
\hline 2 & Groin, $14.9 \%(13.0-16.7)$ & Knee, $12.7 \%(10.5-15.0)$ & Groin, $17.5 \%(14.8-20.6)$ \\
\hline 3 & Ankle, $11.7 \%(10.1-13.3)$ & Ankle, $12.2 \%(9.9-14.2)$ & Ankle, $10.7 \%(8.4-13.3)$ \\
\hline 4 & Knee, 11.1\% (9.5 - 12.6) & Groin, $10.8 \%(8.9-12.9)$ & Quadriceps, $10.1 \%(7.8$ - 12.5) \\
\hline $5 \mathrm{~A}$ & Quadriceps, 9.3\% (7.9 - 10.3) & Shoulder, $9.7 \%(7.9-11.7)$ & Knee, 8.6\% (6.3 - 10.7) \\
\hline $5 B$ & & Quadriceps, 9.7\% (7.7 - 11.6) & - \\
\hline ombined & $70.9 \%(62.4-78.9)$ & $78.2 \%(65.1-91.4)$ & $74.5 \%(61.5-88.3)$ \\
\hline
\end{tabular}




\section{Table 3 (on next page)}

Most common clinical entities as per injury diagnosis 
1 Table 3 - Most common clinical entities as injury diagnosis

\begin{tabular}{|c|c|c|c|c|c|c|c|c|c|}
\hline & $\begin{array}{l}\text { Team } \\
\text { Rate Per } \\
\text { Season } \\
\text { (Median, } \\
\text { IQR) }\end{array}$ & $\begin{array}{l}\text { Percentage of } \\
\text { All Injuries }\end{array}$ & Prevalence & Incidence & $\begin{array}{l}\text { Match-Play } \\
\text { Incidence }\end{array}$ & $\begin{array}{l}\text { Training } \\
\text { Incidence }\end{array}$ & $\begin{array}{l}\text { Likelihood Non- } \\
\text { Contact Related }\end{array}$ & $\begin{array}{l}\text { Likelihood } \\
\text { Occuring in } \\
\text { Match-Play }\end{array}$ & $\begin{array}{l}\text { Likelihood } \\
\text { Occuring in } \\
\text { Training }\end{array}$ \\
\hline All Injuries & $\begin{array}{l}42(31- \\
53)\end{array}$ & - & $\begin{array}{c}69.8 \%(67.4- \\
72.3)\end{array}$ & $\begin{array}{l}9.2(8.8- \\
9.6)\end{array}$ & $\begin{array}{l}50.5(47.2- \\
53.8)\end{array}$ & $\begin{array}{l}3.9(3.6- \\
4.3)\end{array}$ & $\begin{array}{c}72.9 \%(70.7- \\
75.1)\end{array}$ & $\begin{array}{c}55.8 \%(53.4- \\
58.2)\end{array}$ & $\begin{array}{c}38.7 \%(36.3- \\
41.2)\end{array}$ \\
\hline $\begin{array}{l}\text { Hamstring: Muscle/Tendon } \\
\text { Strain }\end{array}$ & $9(7-12)$ & $\begin{array}{c}23.0 \%(21.0- \\
24.9)\end{array}$ & $\begin{array}{c}19.7 \%(17.5- \\
21.8)\end{array}$ & $\begin{array}{l}2.1(1.9- \\
2.3)\end{array}$ & $\begin{array}{l}11.0(9.5- \\
12.5)\end{array}$ & $\begin{array}{l}1.1(0.9- \\
1.2)\end{array}$ & $\begin{array}{c}98.1 \%(96.8- \\
99.5)\end{array}$ & $\begin{array}{c}52.7 \%(48.1- \\
57.7)\end{array}$ & $\begin{array}{c}45.2 \%(40.4- \\
49.7)\end{array}$ \\
\hline Ankle: Sprain & $3(1-4)$ & $6.8 \%(5.6-7.9)$ & $7.4 \%(6.0-8.8)$ & $\begin{array}{l}0.6(0.5- \\
0.7)\end{array}$ & $3.8(2.9-4.7)$ & $\begin{array}{l}0.2(0.2- \\
0.3)\end{array}$ & $\begin{array}{c}80.2 \%(72.1- \\
87.4)\end{array}$ & $\begin{array}{c}62.2 \%(53.2- \\
71.2)\end{array}$ & $\begin{array}{c}32.4 \%(23.4- \\
40.5)\end{array}$ \\
\hline Groin: Adductor-Related & $2(1-4)$ & $5.9 \%(4.8-6.9)$ & $6.0 \%(4.7-7.2)$ & $\begin{array}{l}0.5(0.4- \\
0.7)\end{array}$ & $2.5(1.8-3.3)$ & $\begin{array}{l}0.3(0.2- \\
0.4)\end{array}$ & $\begin{array}{c}94.8 \%(89.6- \\
99.0)\end{array}$ & $\begin{array}{c}47.9 \%(37.9- \\
57.9)\end{array}$ & $\begin{array}{c}46.9 \%(36.9- \\
56.9)\end{array}$ \\
\hline Quadriceps: Muscle Strain & $2(1-4)$ & $5.2 \%(4.2-6.4)$ & $5.8 \%(4.5-7.1)$ & $\begin{array}{l}0.5(0.4- \\
0.6)\end{array}$ & $2.0(1.3-2.6)$ & $\begin{array}{l}0.3(0.2- \\
0.4)\end{array}$ & $\begin{array}{l}98.8 \%(96.5- \\
100)\end{array}$ & $\begin{array}{c}41.2 \%(30.6- \\
50.6)\end{array}$ & $\begin{array}{c}58.8 \%(49.4- \\
69.4)\end{array}$ \\
\hline Calf: Muscle/Tendon Strain & $1(0-4)$ & $4.3 \%(3.4-5.3)$ & $4.5 \%(3.4-5.6)$ & $\begin{array}{l}0.4(0.3- \\
0.5)\end{array}$ & $2.0(1.3-2.7)$ & $\begin{array}{l}0.2(0.1- \\
0.3)\end{array}$ & $\begin{array}{c}94.4 \%(87.3- \\
98.6)\end{array}$ & $\begin{array}{c}50.7 \%(38.0- \\
62.0)\end{array}$ & $\begin{array}{c}47.9 \%(36.6- \\
60.6)\end{array}$ \\
\hline $\begin{array}{l}\text { Quadriceps: } \\
\text { Bruising/Haematoma }\end{array}$ & $1(0-3)$ & $3.9 \%(3.0-4.8)$ & $4.1 \%(3.1-5.2)$ & $\begin{array}{l}0.4(0.3- \\
0.4)\end{array}$ & $2.8(2.1-3.6)$ & $\begin{array}{l}0.1(0.0- \\
0.1)\end{array}$ & $7.9 \%(1.6-15.9)$ & $\begin{array}{c}81.0 \%(71.4- \\
90.5)\end{array}$ & $\begin{array}{c}17.5 \%(7.9- \\
27.0)\end{array}$ \\
\hline Groin: Hip-related & $1(0-3)$ & $2.7 \%(2.0-3.5)$ & $2.9 \%(2.0-3.9)$ & $\begin{array}{c}0.3(0.2- \\
0.3)\end{array}$ & $0.9(0.5-1.3)$ & $\begin{array}{l}0.1(0.1- \\
0.2)\end{array}$ & $\begin{array}{c}68.2 \%(54.5- \\
81.8)\end{array}$ & $\begin{array}{c}35.6 \%(21.6- \\
49.5)\end{array}$ & $\begin{array}{c}46.7 \%(32.1- \\
61.2)\end{array}$ \\
\hline Shoulder AC Joint Sprain & $1(0-2)$ & $2.4 \%(1.7-3.1)$ & $2.9 \%(2.0-3.8)$ & $\begin{array}{c}0.2(0.2- \\
0.3)\end{array}$ & $1.8(1.2-2.5)$ & $\begin{array}{c}0.04(0.0- \\
0.1)\end{array}$ & $\begin{array}{c}15.0 \%(5.0- \\
27.4)\end{array}$ & $\begin{array}{c}82.5 \%(70.0- \\
92.5)\end{array}$ & $\begin{array}{c}15.0 \%(5.0- \\
27.5)\end{array}$ \\
\hline Ankle: General & $1(0-2)$ & $2.4 \%(1.7-3.1)$ & $2.7 \%(1.8-3.6)$ & $\begin{array}{c}0.2(0.2- \\
0.3)\end{array}$ & $1.1(0.6-1.6)$ & $\begin{array}{l}0.1(0.1- \\
0.1)\end{array}$ & $\begin{array}{c}76.9 \%(64.1 \text { - } \\
89.7)\end{array}$ & $\begin{array}{c}51.3 \%(33.3- \\
66.7)\end{array}$ & $\begin{array}{c}41.0 \%(25.6- \\
56.4)\end{array}$ \\
\hline Groin: Other & $1(0-3)$ & $2.3 \%(1.6-3.1)$ & $2.6 \%(1.7-3.4)$ & $\begin{array}{c}0.2(0.2- \\
0.3)\end{array}$ & $0.7(0.3-1.0)$ & $\begin{array}{c}0.1(0.1- \\
0.2)\end{array}$ & $\begin{array}{c}89.5 \%(78.9- \\
97.4)\end{array}$ & $\begin{array}{c}31.6 \%(16.8- \\
46.4)\end{array}$ & $\begin{array}{c}47.4 \%(31.5- \\
63.2)\end{array}$ \\
\hline Groin: Iliopsoas-Related & $1(0-3)$ & $2.1 \%(1.5-2.9)$ & $2.5 \%(1.7-3.3)$ & $\begin{array}{c}0.2(0.1- \\
0.3)\end{array}$ & $0.8(0.4-1.3)$ & $\begin{array}{l}0.1(0.1- \\
0.2)\end{array}$ & $\begin{array}{c}88.6 \%(77.1- \\
97.1)\end{array}$ & $\begin{array}{c}42.9 \%(26.5- \\
59.3)\end{array}$ & $\begin{array}{c}48.6 \%(32.0- \\
65.1)\end{array}$ \\
\hline Knee: Patellar Tendinopathy & $0(0-1)$ & $2.1 \%(1.4-2.8)$ & $2.3 \%(1.5-3.1)$ & $\begin{array}{c}0.2(0.1- \\
0.3)\end{array}$ & $1.3(0.8-1.8)$ & $\begin{array}{c}0.03(0.0- \\
0.1)\end{array}$ & $\begin{array}{c}97.1 \%(91.2- \\
100)\end{array}$ & $\begin{array}{c}67.6 \%(52.9- \\
82.4)\end{array}$ & $\begin{array}{c}11.8 \%(2.9- \\
23.5)\end{array}$ \\
\hline Shoulder: General & $0(0-1)$ & $1.7 \%(1.2-2.3)$ & $2.1 \%(1.3-2.9)$ & $\begin{array}{c}0.2(0.1- \\
0.2)\end{array}$ & $1.0(0.5-1.5)$ & $\begin{array}{c}0.06(0.0- \\
0.1)\end{array}$ & $\begin{array}{c}25.0 \%(7.1- \\
42.9)\end{array}$ & $\begin{array}{c}64.3 \%(46.4- \\
82.1)\end{array}$ & $35.7(17.9-53.6)$ \\
\hline Knee: MCL Sprain & $1(0-2)$ & $1.6 \%(1.0-2.3)$ & $1.7 \%(1.0-2.4)$ & $\begin{array}{c}0.2(0.1- \\
0.2)\end{array}$ & $1.2(0.7-1.7)$ & $\begin{array}{c}0.03(0.0- \\
0.1)\end{array}$ & $\begin{array}{c}42.3 \%(23.1- \\
61.5)\end{array}$ & $\begin{array}{c}80.8 \%(65.4- \\
96.2)\end{array}$ & $\begin{array}{c}15.4 \%(3.8- \\
30.8)\end{array}$ \\
\hline Knee: General & $0(0-1)$ & $1.6 \%(1.0-2.2)$ & $2.0 \%(1.2-2.7)$ & $\begin{array}{c}0.2(0.1- \\
0.2)\end{array}$ & $0.6(0.3-1.0)$ & $\begin{array}{l}0.1(0.0- \\
0.1)\end{array}$ & $\begin{array}{c}61.5 \%(42.4 \text { - } \\
80.8)\end{array}$ & $\begin{array}{c}42.3 \%(23.1 \text { - } \\
61.5)\end{array}$ & $\begin{array}{c}53.8 \%(34.6- \\
73.1)\end{array}$ \\
\hline Back: Disc Pathology & $0(0-1)$ & $1.5 \%(1.0-2.1)$ & $1.7 \%(1.0-2.3)$ & $\begin{array}{c}0.2(0.1- \\
0.2)\end{array}$ & $0.4(0.1-0.8)$ & $\begin{array}{l}0.1(0.0- \\
0.1)\end{array}$ & $\begin{array}{c}96.0 \%(88.0- \\
100)\end{array}$ & $\begin{array}{c}32.0 \%(16.0- \\
52.0)\end{array}$ & $\begin{array}{c}44.0 \%(24.0- \\
64.0)\end{array}$ \\
\hline Knee: Bruising/Haematoma & $0(0-1)$ & $1.5 \%(0.9-2.2)$ & $2.5 \%(1.7-3.3)$ & $\begin{array}{l}0.2(0.1- \\
0.3)\end{array}$ & $1.3(0.8-1.8)$ & $\begin{array}{c}0.06(0.0- \\
0.1)\end{array}$ & $\begin{array}{c}37.1 \%(22.9- \\
54.3)\end{array}$ & $\begin{array}{c}65.7 \%(48.6- \\
82.8)\end{array}$ & $\begin{array}{c}25.7 \%(11.4- \\
40.0)\end{array}$ \\
\hline
\end{tabular}




\section{Table 4 (on next page)}

Consequences of the most common clinical entities

*Likelihood of recurrence statistic in row "All Injuries" refers to proportion of players sustaining a subsequent injury following a return to sport. 
1 Table 4 - Consequences of the most common clinical entities

\begin{tabular}{|c|c|c|c|c|c|}
\hline & $\begin{array}{l}\text { Mean Time- } \\
\text { Loss }\end{array}$ & Injury Burden & $\begin{array}{l}\text { Percentage of } \\
\text { Unavailability }\end{array}$ & $\begin{array}{l}\text { Likelihood of } \\
\text { Recurrence }\end{array}$ & $\begin{array}{l}\text { Match-Play } \\
\text { Incidence }\end{array}$ \\
\hline All Injuries & $25.9(23.5-28.4)$ & $238.3(206.8-272.6)$ & - & $71.8 \%(63.5-80.2)^{*}$ & $50.5(47.2-53.8)$ \\
\hline Hamstring: Muscle/Tendon Strain & $25.2(20.5-31.0)$ & $52.9(39.0-71.3)$ & $22.2 \%(18.8-26.2)$ & $44.1 \%(38.0-50.1)$ & $11.0(9.5-12.5)$ \\
\hline Ankle: Sprain & $24.5(18.1-32.9)$ & $14.7(9.1-23.0)$ & $6.2 \%(4.4-8.4)$ & $13.3 \%(6.5-20.0)$ & $3.8(2.9-4.7)$ \\
\hline Groin: Adductor-Related & $25.3(15.9-37.1)$ & $12.7(6.4-26.0)$ & $5.3 \%(3.1-9.5)$ & $21.5 \%(12.5-30.6)$ & $2.5(1.8-3.3)$ \\
\hline Quadriceps: Muscle Strain & $24.7(15.5-38.9)$ & $12.4(6.2-23.3)$ & $5.2 \%(3.0-8.6)$ & $10.4 \%(3.6-17.2)$ & $2.0(1.3-2.6)$ \\
\hline Calf: Muscle/Tendon Strain & $29.2(19.2-42.3)$ & $11.7(5.8-21.2)$ & $4.9 \%(2.8-7.8)$ & $18.3 \%(8.5-28.1)$ & $2.0(1.3-2.7)$ \\
\hline Quadriceps: Bruising/Haematoma & $9.7(7.8-11.9)$ & $3.9(2.3-4.8)$ & $1.6 \%(1.1-1.7)$ & $14.5 \%(5.2-23.9)$ & $2.8(2.1-3.6)$ \\
\hline Groin: Hip-related & $32.1(19.0-47.3)$ & $9.6(3.8-14.2)$ & $4.0 \%(1.8-5.2)$ & $12.8 \%(2.3-23.3)$ & $0.9(0.5-1.3)$ \\
\hline Shoulder AC Joint Sprain & $34.2(20.0-54.0)$ & $6.8(4.0-16.2)$ & $2.9 \%(1.9-5.9)$ & $5.3 \%(1.8-12.4)$ & $1.8(1.2-2.5)$ \\
\hline Ankle: General & $26.8(17.7-38.3)$ & $5.4(3.5-11.5)$ & $2.2 \%(1.7-4.2)$ & $8.3 \%(0.7-17.4)$ & $1.1(0.6-1.6)$ \\
\hline Groin: Other & $18.1(9.7-29.1)$ & $3.6(1.9-8.7)$ & $1.5 \%(0.9-3.2)$ & $11.8 \%(0.9-22.6)$ & $0.7(0.3-1.0)$ \\
\hline Groin: Iliopsoas-Related & $13.3(10.1-17.1)$ & $2.7(1.0-5.1)$ & $1.1 \%(0.5-1.9)$ & $6.1 \%(2.1-14.2)$ & $0.8(0.4-1.3)$ \\
\hline Knee: Patellar Tendinopathy & $41.7(22.7-64.3)$ & $8.3(2.3-19.3)$ & $3.5 \%(1.1-7.1)$ & $20.0 \%(5.7-34.3)$ & $1.3(0.8-1.8)$ \\
\hline Shoulder: General & $15.8(10.9-20.8)$ & $3.2(1.1-4.2)$ & $1.3 \%(0.5-1.5)$ & None Registered & $1.0(0.5-1.5)$ \\
\hline Knee: MCL Sprain & $32.2(22.0-43.4)$ & $6.4(2.2-8.7)$ & $2.7 \%(1.1-3.2)$ & $13.0 \%(0.7-26.8)$ & $1.2(0.7-1.7)$ \\
\hline Knee: General & $19.5(12.1-27.3)$ & $3.9(1.2-5.5)$ & $1.6 \%(0.6-2.0)$ & None Registered & $0.6(0.3-1.0)$ \\
\hline Back: Disc Pathology & $41.9(12.9-85.1)$ & $8.4(1.3-17.0)$ & $3.5 \%(0.6-6.2)$ & $13.6 \%(0.7-28.0)$ & $0.4(0.1-0.8)$ \\
\hline Knee: Bruising/Haematoma & $18.8(10.7-31.3)$ & $3.8(1.1-6.3)$ & $1.6 \%(0.5-3.4)$ & $6.1 \%(2.1-14.2)$ & $1.3(0.8-1.8)$ \\
\hline
\end{tabular}




\section{Table 5 (on next page)}

Frequency and nature of match-play and training injuries per 1000 hours

Incidence rate ratio (IRR). 
Table 5 - Frequency and Nature of Match-Play and Training Injuries

2

\begin{tabular}{|c|c|c|c|c|c|c|c|}
\hline & \multicolumn{7}{|c|}{ Match-Play Injuries } \\
\hline & Incidence & Non-Contact & Contact & NC : C IRR & Acute & $\begin{array}{c}\text { Chronic/Overu } \\
\text { se }\end{array}$ & A : C/O IRR \\
\hline $\begin{array}{l}\text { All } \\
\text { Regions }\end{array}$ & $49.8(46.5-53.0)$ & $29.1(26.6$ - 31.6) & $21.0(18.6-22.8)$ & $1.41(1.23-1.60)$ & $41.9(38.9$ - 38.9) & $7.8(6.5-9.1)$ & $5.35(4.48-6.39)$ \\
\hline $\begin{array}{l}\text { Lower } \\
\text { Limb }\end{array}$ & $38.7(35.8-41.6)$ & $25.5(23.2$ - 27.9) & $13.2(11.5-14.9)$ & $1.94(1.66-2.26)$ & $31.7(29.1$ - 34.3) & $7.0(5.8-8.2)$ & $4.52(3.74-5.48)$ \\
\hline $\begin{array}{l}\text { Upper } \\
\text { limb }\end{array}$ & $7.1(5.8-8.3)$ & $2.4(1.7-3.1)$ & $4.7(3.7-5.7)$ & $0.51(0.3-0.74)$ & $6.6(5.4-7.7)$ & $0.5(0.2-0.8)$ & $\begin{array}{c}13.11(6.66- \\
25.81)\end{array}$ \\
\hline Trunk & $2.5(1.7-3.2)$ & $1.2(0.7-1.7)$ & $1.3(0.8-1.8)$ & $0.91(0.51-1.65)$ & $2.1(1.4-2.8)$ & $0.3(0.1-0.6)$ & $\begin{array}{c}6.33(2.68- \\
14.98)\end{array}$ \\
\hline \multirow[t]{3}{*}{ Head/Neck } & $1.6(1.0-2.1)$ & - & $1.6(1.0-2.1)$ & - & $1.6(1.0-2.1)$ & - & - \\
\hline & \multicolumn{7}{|c|}{ Training Injuries } \\
\hline & Incidence & Non-Contact & Contact & NC : C IRR & Acute & $\begin{array}{c}\text { Chronic/Overu } \\
\text { se }\end{array}$ & A : C/O IRR \\
\hline $\begin{array}{l}\text { All } \\
\text { Regions }\end{array}$ & $3.9(3.5-4.2)$ & $2.7(2.4-3.0)$ & $1.2(1.0-1.3)$ & $2.34(1.97-2.78)$ & $2.9(2.7-3.2)$ & $0.9(0.8-1.1)$ & $3.24(2.69-3.90)$ \\
\hline $\begin{array}{l}\text { Lower } \\
\text { Limb }\end{array}$ & $3.2(2.9-3.5)$ & $2.4(2.2-2.7)$ & $0.8(0.7-0.9)$ & $3.02(2.48-3.69)$ & $2.4(2.2-2.7)$ & $0.8(0.7-1.0)$ & $2.99(2.45-3.65)$ \\
\hline $\begin{array}{l}\text { Upper } \\
\text { limb }\end{array}$ & $0.2(0.2-0.3)$ & $0.1(0.0-0.1)$ & $0.2(0.1-0.2)$ & $0.44(0.23-0.88)$ & $0.2(0.2-0.3)$ & $\begin{array}{c}0.02(0.00- \\
0.04)\end{array}$ & $\begin{array}{c}12.00(3.70- \\
38.97)\end{array}$ \\
\hline Trunk & $0.3(0.2-0.4)$ & $0.2(0.1-0.2)$ & $0.1(0.1-0.2)$ & $1.71(0.94-3.10)$ & $0.2(0.1-0.3)$ & $0.1(0.0-0.1)$ & $2.54(1.34-4.82)$ \\
\hline Head/Neck & $0.1(0.1-0.1)$ & $0.02(0.00-0.04)$ & $0.1(0.0-0.1)$ & $0.25(0.07-0.89)$ & $0.1(0.1-0.1)$ & - & - \\
\hline
\end{tabular}


Table 6 (on next page)

Injury severity

Incidence rate ratio (IRR). 
Table 6 - Incidence Rate Ratio Comparing Frequency of Match-Play to Training Injuries Per Type

\begin{tabular}{|c|c|c|c|c|c|c|c|c|}
\hline & IRR & Non-Contact & Contact & Acute & Chronic/Overuse & Mild & Moderate & Severe \\
\hline All Regions & $12.93(11.69-14.32)$ & $10.78(9.50-12.24)$ & $17.97(15.07-21.43)$ & $14.26(12.72-15.98)$ & $8.64(6.86-10.89)$ & $10.94(9.00-13.29)$ & $13.26(11.48-15.31)$ & $15.98(12.78-19.99)$ \\
\hline Lower Limb & $12.01(10.73-13.45)$ & $10.54(9.22-12.06)$ & $16.46(13.28-20.39)$ & $13.12(11.54$ - 14.92) & $8.68(6.79-11.09)$ & $10.50(8.44-13.05)$ & $11.78(1.07-13.79)$ & $14.90(11.58-19.18)$ \\
\hline Upper limb & $28.94(20.22-41.42)$ & $31.85(16.80-60.38)$ & $27.65(17.93-42.65)$ & $29.13(20.06-42.29)$ & $26.66(7.22-98.46)$ & $33.01(14.33-76.04)$ & $23.96(14.85-38.65)$ & $61.22(30.43-123.16)$ \\
\hline Trunk & $8.50(5.62-12.85)$ & $6.44(3.67-11.28)$ & $12.02(6.43-22.50)$ & $10.23(6.42-16.31)$ & $4.10(1.56-10.79)$ & $5.43(2.57-11.50)$ & $19.39(9.50$ - 39.50) & $8.00(3.25-19.68)$ \\
\hline Head/Neck & $16.59(8.86-31.05)$ & - & $20.74(10.55-40.77)$ & $16.59(8.86-31.05)$ & - & $12.22(4.92-30.38)$ & $41.47(11.92-144.31)$ & $11.85(2.65-52.94)$ \\
\hline
\end{tabular}




\section{Table 7 (on next page)}

Time-loss per activity

Mild (1-7 days), moderate (8-28 days), severe (29+ days). Incidence reported per 1000 exposure hours. 
Table 7 - Injury Severity

2

\begin{tabular}{|c|c|c|c|c|c|c|}
\hline & Mild & Moderate & Severe & Mild Incidence & Moderate Incidence & Severe Incidence \\
\hline All Injuries & $27.0 \%(24.4-29.5)$ & $49.8 \%(47.0-53.0)$ & $23.2 \%(20.6-25.7)$ & $2.5(2.2-2.7)$ & $4.5(4.2-4.8)$ & $2.1(1.9-2.3)$ \\
\hline Lower limb & $26.6 \%(23.4-29.5)$ & $50.8 \%(47.4-54.2)$ & $22.6 \%(19.9-25.6)$ & $1.9(1.7-2.1)$ & $3.7(3.4-4.0)$ & $1.6(1.5-1.8)$ \\
\hline Upper Limb & $19.8 \%(12.5-28.1)$ & $51.0 \%(40.6-60.4)$ & $29.2 \%(19.8-38.5)$ & $0.1(0.1-0.2)$ & $0.3(0.2-0.4)$ & $0.2(0.1-0.2)$ \\
\hline Trunk & $35.8 \%(25.4-46.3)$ & $40.3 \%(28.3-52.2)$ & $23.9 \%(13.4-34.3)$ & $0.2(0.2-0.3)$ & $0.2(0.2-0.3)$ & $0.1(0.1-0.2)$ \\
\hline Head/Neck & $44.0 \%(24.0-64.0)$ & $40.0 \%(20.0-60.0)$ & $16.0 \%(4.0-32.0)$ & $0.1(0.1-0.2)$ & $0.1(0.1-0.2)$ & $0.1(0.0-0.1)$ \\
\hline Training Injuries & $30.2 \%(26.0-34.6)$ & $50.4 \%(45.4-55.0)$ & $19.4 \%(15.7-23.3)$ & $1.1(1.0-1.3)$ & $1.9(1.7-2.1)$ & $0.7(0.6-0.9)$ \\
\hline Lower limb & $28.9 \%(24.1-33.7)$ & $52.4 \%(46.5-57.5)$ & $18.7 \%(15.0-22.9)$ & $0.9(0.8-1.1)$ & $1.7(1.5-1.9)$ & $0.6(0.5-0.7)$ \\
\hline Upper Limb & $17.6 \%(0.0-35.3)$ & $58.8 \%(35.3-82.4)$ & $23.5 \%(5.9-41.2)$ & $0.04(0.01-0.08)$ & $0.14(0.09-0.20)$ & $0.06(0.02-0.09)$ \\
\hline Trunk & $46.4 \%(28.6-64.3)$ & $28.6 \%(10.7-46.4)$ & $25.0 \%(10.7-42.9)$ & $0.11(0.06-0.16)$ & $0.07(0.03-0.11)$ & $0.06(0.02-0.10)$ \\
\hline Head/Neck & $55.6 \%(22.2-88.9)$ & $22.2 \%(0.0-55.6 \%)$ & $22.2 \%(0.0-55.6 \%)$ & $0.05(0.02-0.08)$ & $0.02(0.00-0.04)$ & $0.02(0.00-0.04)$ \\
\hline Match-Injuries & $25.1 \%(21.7-28.7)$ & $51.1 \%(47.0-55.2)$ & $23.8 \%(20.3-27.0)$ & $12.5(10.8-14.1)$ & $25.5(23.1$ - 27.8) & $11.9(10.3-13.5)$ \\
\hline Lower limb & $25.3 \%(21.2-29.2)$ & $51.5 \%(47.0-56.3)$ & $23.2 \%(19.3-26.8)$ & $9.8(8.3-11.2)$ & $19.9(17.8-22.0)$ & $9.0(7.6-10.3)$ \\
\hline Upper Limb & $20.5 \%(1.5-29.5)$ & $48.7 \%(37.2-60.3)$ & $30.8 \%(20.5-41.0)$ & $1.5(0.9-2.0)$ & $3.5(2.6-4.3)$ & $2.2(1.5-2.9)$ \\
\hline Trunk & $25.0 \%(10.7-42.9)$ & $53.6 \%(35.7-71.4)$ & $21.4 \%(7.1-35.7)$ & $0.6(0.3-1.0)$ & $1.3(0.8-1.9)$ & $0.5(0.2-0.8)$ \\
\hline Head/Neck & $37.5 \%(18.8-62.5)$ & $50.0 \%(25.0-75.0)$ & $12.5 \%(7.1-35.7)$ & $0.6(0.3-1.0)$ & $0.8(0.4-1.2)$ & $0.2(0.0-0.4)$ \\
\hline
\end{tabular}




\section{Table 8 (on next page)}

Time-loss and injury burden per activity

Match-play (MP), training (TR), relative ratio (RR). 
Table 8 - Time-Loss Per Activity

\begin{tabular}{|c|c|c|c|c|c|c|c|}
\hline & \multicolumn{3}{|c|}{ Mean Time-Loss Days } & \multicolumn{3}{|c|}{ Percentage of All Time-Loss } & \multirow[b]{2}{*}{ Injury Burden MP : TR RR } \\
\hline & All Injuries & Match-Play & Training & All Injuries & Match-Play & Training & \\
\hline All Regions & $25.7(23.4-28.3)$ & $24.0(21.6-26.6)$ & $22.8(19.3-27.2)$ & - & $51.8 \%(51.2-52.1)$ & $39.5 \%(36.7-42.8)$ & $13.44(12.34-14.87)$ \\
\hline Lower Limb & $25.4(22.8-28.5)$ & $23.5(21.1-26.4)$ & $22.6(18.9-27.2)$ & $79.1 \%(77.9-80.6)$ & $76.1 \%(76.0-77.2)$ & $83.0 \%(82.0-83.7)$ & $12.58(11.54-13.78)$ \\
\hline Upper limb & $28.8(22.5-36.4)$ & $29.9(22.3-38.3)$ & $23.7(16.8-31.3)$ & $11.2 \%(9.6-12.8)$ & $17.7 \%(14.6-20.4)$ & $6.6 \%(5.5-7.3)$ & $44.79(38.49-54.50)$ \\
\hline Trunk & $28.9(18.6-42.6)$ & $22.4(13.3-35.8)$ & $27.0(13.4-45.2)$ & $7.4 \%(5.2-9.9)$ & $4.6 \%(3.0-6.6)$ & $8.9 \%(5.2-12.4)$ & $6.94(6.34-8.44)$ \\
\hline Head/Neck & $13.3(8.8-18.2)$ & $11.8(7.8-17.4)$ & $16.0(7.5-25.3)$ & $1.8 \%(1.3-2.2)$ & $1.5 \%(1.1-2.0)$ & $1.7 \%(0.9-2.3)$ & $11.80(10.4-14.44)$ \\
\hline
\end{tabular}

